\title{
SNP rs1801157 significantly correlates with distant metastasis in CXCL12 expressing esophagogastric cancer
}

\author{
CARL C. SCHIMANSKI ${ }^{1,2^{*}}$, MAREIKE JORDAN ${ }^{1 *}$, FRIEDERIKE SCHLAEGEL ${ }^{1}$, IRENE SCHMIDTMANN ${ }^{4}$, \\ HAUKE LANG $^{3}$, PETER R. GALLE ${ }^{2}$, MARKUS MOEHLER ${ }^{2}$ and INES GOCKEL ${ }^{1,3}$ \\ ${ }^{1}$ Interdisciplinary Translational Oncologic Laboratory (ITOL), ${ }^{2}$ I. Medical Clinic and Policlinic, \\ ${ }^{3}$ Department of General and Abdominal Surgery, and ${ }^{4}$ Institute of Medical Biostatistics, Epidemiology \\ and Informatics (IMBEI), Johannes Gutenberg University Hospital, Mainz, Germany
}

Received March 9, 2011; Accepted April 26, 2011

DOI: 10.3892/ijo.2011.1044

\begin{abstract}
We performed this study in order to evaluate the impact of the chemokine CXCL12 and its single-nucleotide polymorphism (SNP) rs1801157 on clinicopathological parameters and survival in patients undergoing surgery for esophagogastric cancer. The expression pattern of CXCL12 and its polymorphisms were analyzed by RT-PCR and PCR-RFLP in 69 consecutive fresh-frozen samples of human esophagogastric junction and gastric adenocarcinomas and statistically analyzed. Expression of the CXCL12 (SNP rs1801157) polymorphisms GA/AA significantly correlated with distant metastasis $(\mathrm{P}=0.026)$, but not with prognosis. However, CXCL12 expression was not significantly associated with the tumor infiltration depth, lymphatic metastasis and grading. As CXCL12 polymorphisms mediate tumor cell dissemination in esophagogastric cancer, they could represent a marker indicating advanced disease. Antagonists targeting the CXCL12/ CXCR4 axis may be a novel therapeutic option in this entity.
\end{abstract}

\section{Introduction}

Chemokines are small secretory proteins that control migration and activation of leukocytes and other cell types through interaction with a group of seven-transmembrane $\mathrm{G}$ proteincoupled receptors (1). It is well known that chemokines might promote tumor growth, dissemination, metastasis and survival in various malignancies (2-6).

The chemokine CXCL12, also known as stromal cellderived factor-1 (SDF-1), is a small protein that regulates

Correspondence to: Dr Carl Christoph Schimanski and Dr Ines Gockel, Interdisciplinary Oncological Laboratory (ITOL), Langenbeckstr. 1, 55131 Mainz, Germany

E-mail: schimanski@1-med.klinik.uni-mainz.de

E-mail: ines.gockel@unimedizin-mainz.de

${ }^{*}$ Contributed equally

Key words: esophagogastric cancer, polymorphisms of chemokine CXCL12, tumor dissemination, prognosis leukocyte trafficking and is variably expressed in a number of normal and cancerous tissues. It has also been reported that the chemokine/chemokine receptor (CXCL12/CXCR4) pathway is involved in tumor development and metastasis (7,8). CXCL12 secretion by stromal cells attracts cancer cells via activation of the CXCR4 receptor-mediated pathways. CXCL12-induced activation of CXCR4 regulates the pattern of metastatic spread. Organs expressing high levels of CXCL12 have a high risk of secondary tumors, mediated through chemo-attraction. Whereas it was previously shown that CXCR4 expression is associated with the malignant behaviour in colorectal (9), esophageal (10), pancreatic (11) and hepatocellular cancers (12), reports in gastric cancers are sparse on the expression profile of CXCL12 (13), in particular with regard to its polymorphisms in gastric adenocarcinoma. Thus, the aim of this study was to evaluate the impact of CXCL12 and its polymorphisms on local tumor infiltration, lymphatic and distant metastasis, as well as survival in patients undergoing surgery for esophagogastric cancer.

\section{Patients and methods}

Tissue source and cell lines. Sixty-nine consecutive patients undergoing standard abdominal gastrectomy or transhiatally extended gastrectomy with systematic D2-lymphadenectomy for gastric cancer and cancer of the esophagogastric junction (Siewert AEG types II and III) were enrolled in this study between 2004 and 2007. The patients had been followed up until January 2010 or until death. Their written informed consent was given and fresh-frozen tissue storage and analysis was approved by the local ethics committee. Twenty-six (38\%) of patients were females and $43(62 \%)$ were males. Mean age at the time of surgery was $66.6( \pm 11.1 \mathrm{SD}$ ) years (range $36-84)$. Fifty patients $(72.5 \%)$ revealed sub-cardial gastric adenocarcinoma, whereas 19 (27.5\%) displayed adenocarcinoma of the cardia (AEG type II according to Siewert). Tissue specimens were conventionally stored in formalin for standard histopathological analysis and were routinely worked-up according to the UICC guidelines with respect to TNM-classification (6th edition, 2002), UICC-stage, and grading.

Small samples of each specimen, taken from a non-necrotic part of the tumor, were immediately extracted at the time of gastrectomy and stored in cryovials, shock frozen in liquid 
nitrogen and stored at $-80^{\circ} \mathrm{C}$ until further processing. As control tissues, diverse gastric (MKN; OE33, NCI N87, Snu16, AGS) and colorectal (SW480, SW620, LST, HT29, L174) cancer cell lines were cultured. Cells were cultured in DMEM (Invitrogen, Germany) supplemented with $10 \%$ FCS, $100 \mathrm{U} / \mathrm{ml}$ penicillin, $100 \mu \mathrm{g} / \mathrm{ml}$ streptomycin (Cambrex, Germany) and $1 \mathrm{mmol} / \mathrm{l} \mathrm{L}$-glutamine (Invitrogen). Reference PCR with $\beta$-actin was performed using these cell lines as shown in Fig. 1.

RNA isolation and CXCL-12-specific RT-PCR. The expression pattern of CXCL12 was analyzed by RT-PCR in cancer cell lines and in 69 consecutive samples of (esophago-) gastric adenocarcinoma and correlated with TNM-classification, grading and survival. RNA isolation was performed using the RNeasy Kit according to the manufacturer's recommendations (Qiagen, Hilden, Germany). For reverse transcription, we used $2 \mu \mathrm{g}$ of RNA (20 $\mu \mathrm{l}$ total volume; Omniscript RT Kit, Qiagen) according to the recommendations of the manufacturer. In total, $0.5 \mu 1$ of cDNA (50 ng) was used as template for the specific PCR reactions. The primers applied with the sequences, as well as temperature used and numbers of cycles were: CXCL-12 forward (5'-CAG TCA ACC TGG GCA AAG CC-3') and CXCL-12 reverse (5'-AGC TTT GGT CCT GAG AGT CC-3') annealed at $62.4^{\circ} \mathrm{C}$ for 35 cycles. $\beta$-actin: forward (5'-TGA CGG GGT CAC CCA CAC TGT GCC CAT CTA-3'), reverse (5'-CTA GAA GCA TTT GCG GTG GAC GAC GGA GGG-3') annealed at $58^{\circ} \mathrm{C}$ for 28 cycles.

For amplification, a DNA Engine PTC200 (MJ Research, Watertown, MA) thermocycler was used. After the last cycle, a final extension $\left(7 \mathrm{~min}\right.$ at $\left.72^{\circ} \mathrm{C}\right)$ was added and thereafter the samples were kept at $4^{\circ} \mathrm{C}$. The product $(7 \mu \mathrm{l})$ was run on a $1.8 \%$ agarose gel, stained by ethidium bromide, and analyzed under UV light. For quantification the 100 bp DNA ladder (Invitrogen) was used. The evaluation of expression was performed semi-quantitatively according to the following grades: 0 , negative; 1 , weak (density beneath $300 \mathrm{bp}$ fragment of ladder; $<30 \mathrm{ng} / \mu \mathrm{l}$ ); 2 , medium (density between $300 \mathrm{bp}$ and $600 \mathrm{bp}$ fragment of ladder; 30-70 ng/ $\mu \mathrm{l}$ ); 3 , strong (density above $600 \mathrm{bp}$ fragment of ladder; $>70 \mathrm{ng} / \mu \mathrm{l}$ ).

RFLP for CXCL12 SNP rs 1801157. The SNP rs1801157 was detected by highly sensitive PCR-RFLP assay. CXCL12 PCR was performed as described above. For RFLP the restriction enzyme MSPI (Moraxella species; Fermentas, Canada) was used. MSPI recognizes DNA at the following specific sequence. The restriction scheme is marked by the arrows. $5^{\prime}$... $\mathrm{C}_{\downarrow} \mathrm{C}$ G G...3'; 3'...G G $\mathrm{C}_{\uparrow} \mathrm{C} . . .5$ '. Only wild-type (GG) DNA sequences were cut, while the mutated strands (containing GA and AA) were not affected. For the restriction, the following conditions were adopted: $15 \mu \mathrm{l}$ of the CXCL12 PCR product were digested with $1 \mu 1$ MSPI in a total volume of $31 \mu 1$ (including Y+/TangoTM yellow buffer and RNase-free water) according to the manufacturer's recommendations (Fermentas, Canada). The digestion was performed for $1 \mathrm{~h}$ at $37^{\circ} \mathrm{C}$ in a thermocycler as described above. After digestion, the product was cooled down and kept at $4^{\circ} \mathrm{C}$ until further processing.

The digested DNA was transmitted on a $3.5 \%$ agarose gel (Top Vision, Fermentas), stained by ethidium bromide. Voltage was applied and after $1 \mathrm{~h}$, the results were visualized under

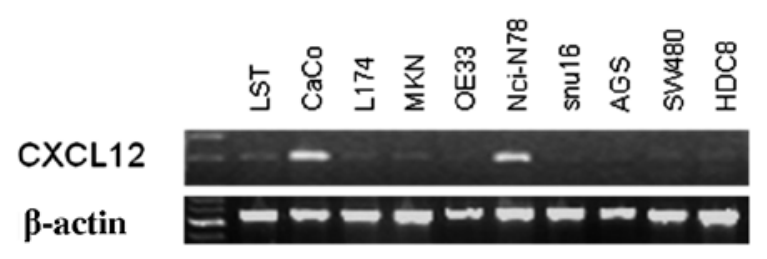

Figure 1. Reference PCR: cell lines expressing $\beta$-actin and CXCL12.

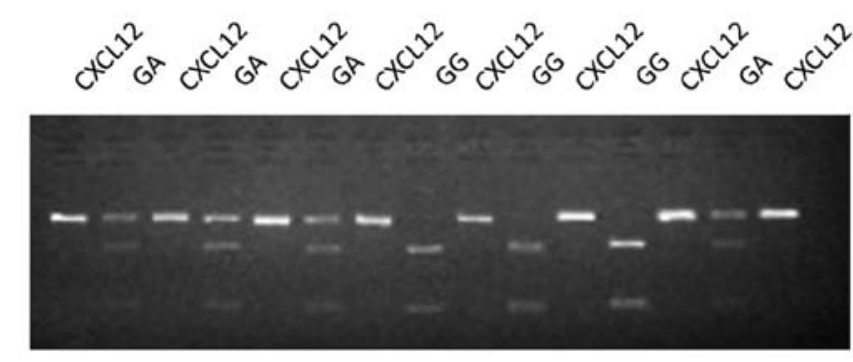

Figure 2. CXCL12 PCR and CXCL12 digestion side by side. On the left hand side the PCR amplification, and next to it on the right hand side, the digestion of this amplification was applied.

UV light. The evaluation was based on the following guidelines: 1 band of 302 bp size AA, three bands of $100 \mathrm{bp}$, 202 and 302 bp size GA, two bands of 100 and 202 size GG. Results of RFLP and PCR of CXCL12 are illustrated in Fig. 2.

Statistical analysis. The SSPS 18.0 software package was used for statistical data analysis (SSPS, Chicago, IL, USA, 2010). Clinicopathological data were prospectively collected in a database established for internal quality control and analyzed retrospectively. The presented data are expressed as the mean values with standard deviation $( \pm \mathrm{SD})$ and ranges (minimum-maximum). In the comparative analysis, the association of categorical data were described in cross tabulations, Fisher's exact test was used for comparisons. The MannWhitney U test served as the non-parametric method to compare quantitative variables between groups. Survival probabilities were estimated with the method of Kaplan and Meier, and a log-rank test was carried out to determine significant differences between the patient groups. Spearman's correlation was used to analyze the influence of CXCL12 on ordinal clinicopathological parameters. Logistic regression was performed as multivariate analysis in order to determine independent parameters with impact on metastasis (M1). $\mathrm{P}<0.05$ was considered significant for all parameters. We did not correct for multiple testing as the main interest was in identifying potential associations. Therefore only the error rate per comparison is controlled.

\section{Results}

Patients' characteristics. Demographic data and patient tumor characteristics are presented in Table I. Unexpectedly, 20\% $(n=14)$ of patients revealed M1-situation at the time of surgery. Out of these, $n=2$ underwent emergency surgery due to tumor bleeding, $n=2$ due to stenosis, $n=1$ patient showed intolerance of chemotherapy. The remaining 9 patients, contrary to pre- 
Table I. Demographic data and patients' tumor characteristics.

\begin{tabular}{|c|c|}
\hline \multicolumn{2}{|c|}{ Age at surgery (years) } \\
\hline Mean \pm SD & $66.6 \pm 11.1$ \\
\hline Range & $36-84$ \\
\hline \multicolumn{2}{|l|}{ Gender n $(\%)$} \\
\hline Females & $26(38)$ \\
\hline Males & $43(62)$ \\
\hline \multicolumn{2}{|c|}{ pT-category n (\%) } \\
\hline pT1 & $7(10)$ \\
\hline pT2 & $32(46)$ \\
\hline pT3 & $26(38)$ \\
\hline pT4 & $4(6)$ \\
\hline \multicolumn{2}{|c|}{ pN-category n (\%) } \\
\hline pNO & $20(29)$ \\
\hline pN1 & $23(33)$ \\
\hline $\mathrm{pN} 2$ & $14(20)$ \\
\hline pN3 & $12(17)$ \\
\hline \multicolumn{2}{|c|}{ pM-category n (\%) } \\
\hline pM0 & $55(80)$ \\
\hline pM1 & $14(20)$ \\
\hline \multicolumn{2}{|c|}{ pR-classification n (\%) } \\
\hline $\mathrm{pR} 0$ & $65(94)$ \\
\hline pR1 & $4(6)$ \\
\hline \multicolumn{2}{|l|}{ Grading n (\%) } \\
\hline G1 & $1(1)$ \\
\hline $\mathrm{G} 2$ & $19(28)$ \\
\hline G3 & $45(65)$ \\
\hline G4 & $3(4)$ \\
\hline Gx & $1(1)$ \\
\hline
\end{tabular}

operative staging, had a local peritoneal carcinomatosis in the omentum minus, omentum majus or liver metastases, which became evident at surgery and were resected in toto. Median survival was 819 days; $95 \%$ confidence interval (263 days; 1374 days).

CXCL12 expression. The semi-quantitative expression patterns of CXCL12 and its polymorphisms varied markedly (Table II). While $17 \%$ of patients did not reveal any CXCL12 expression, a weak CXCL12 expression was seen in 19\%, an intermediate expression in $30 \%$ and a strong expression in $33 \%$ of samples.
Table II. Expression patterns of CXCL12 and incidence of its polymorphisms.

\begin{tabular}{lcccc}
\hline & 0, absent & 1, weak & 2, medium & 3, strong \\
\hline $\begin{array}{l}\text { CXCL12 } \\
\text { n (\%) }\end{array}$ & $12(17)$ & $13(19)$ & $21(30)$ & $23(33)$ \\
\hline & $\begin{array}{c}\text { No CXCL12- } \\
\text { expression }\end{array}$ & AA & GA & GG; wt \\
\hline $\begin{array}{l}\text { CXCL12-SNP } \\
\text { n (\%) }\end{array}$ & $16(23)$ & $5(7)$ & $13(19)$ & $33(48)$ \\
\hline
\end{tabular}

The polymorphism occurred in $7 \%$ as AA, in $19 \%$ as GA, and in $48 \%$ the wild-type GG was expressed.

Correlation of CXCL12 and its polymorphisms with clinicopathological parameters and prognosis. Among histopathological parameters, only $\mathrm{pN}$-category $(\mathrm{P}=0.024)$ was significantly associated with overall survival. pT-category $(\mathrm{P}=0.164)$, $\mathrm{pM}$-category $(\mathrm{P}=0.121)$ as well as tumor grading $(\mathrm{P}=0.734)$ did not exert a significant influence on prognosis. Expression of CXCL12 did neither correlate with the pT-, pN-, pM-classification nor with tumor grading (Table III). In contrast, CXCL12 polymorphisms (GA/AA) was significantly correlated with distant metastasis $(\mathrm{P}=0.026)$, whereas tumor infiltration depth, lymphatic metastasis and grading were not significantly associated (Table III).

With regard to expression of CXCL12 (0 vs. 1 vs. 2 vs. 3, $\mathrm{P}=0.181)$, (0 vs. $1 / 2 / 3, \mathrm{P}=0.864)$ and its polymorphisms 0 vs. GG vs. GA vs. AA $(\mathrm{P}=0.778)$ and 0 vs. $G G$ vs. GA/AA $(\mathrm{P}=0.578)$, none of them displayed a statistically significant influence on prognosis. Kaplan-Meier survival curves for CXCL12 and CXCL12 polymorphism (0 vs. GG vs. GA/AA) are illustrated in Fig. 3 (CXCL12 polymorphism) and Fig. 4 (CXCL12).

Association of CXCL12 and CXCL12 polymorphism with localisation of the tumor. While CXCL12 expression was associated with a tumor localisation in the esophagogastric junction and all of these patients expressed CXCL12 $(\mathrm{P}=0.001)$, CXCL12 polymorphism (GA/AA) occurred primarily in the subcardial site $(94 \%(\mathrm{n}=17) ;(\mathrm{P}=0.027)$. Results are demonstrated in Table III.

Table III. Spearman's correlations between CXCL12 and histopathological parameters. ${ }^{\mathrm{a}}$

\begin{tabular}{|c|c|c|c|c|}
\hline & pT-category & pN-category & pM-category & Grading \\
\hline CXCL12 & $0.019 \mathrm{P}=0.878$ & $-0.156 \mathrm{P}=0.199$ & $0.082 \mathrm{P}=0.503$ & $-0.015 \mathrm{P}=0.905$ \\
\hline $\begin{array}{l}\text { CXCL12-polymorphism } \\
\left(0 \text { vs. GG = wild-type vs. GA, } A^{c}\right)\end{array}$ & $\mathrm{P}=0.465$ & $\mathrm{P}=0.382$ & $\mathrm{P}=0.026^{\mathrm{b}}$ & $\mathrm{P}=0.813$ \\
\hline
\end{tabular}


CXCL12 Polymorphism (GG vs. GA and AA)

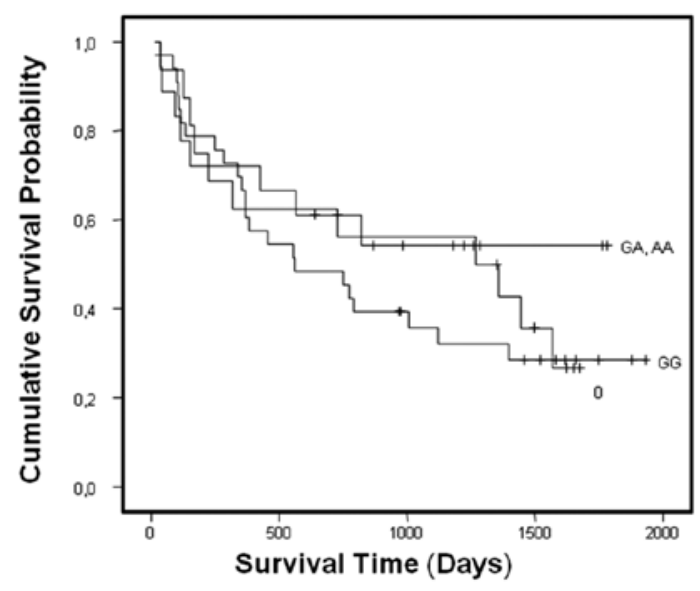

Figure 3. Survival of 0 vs. wild-type (GG) vs. mutation (GA, AA).

\section{CXCL12}

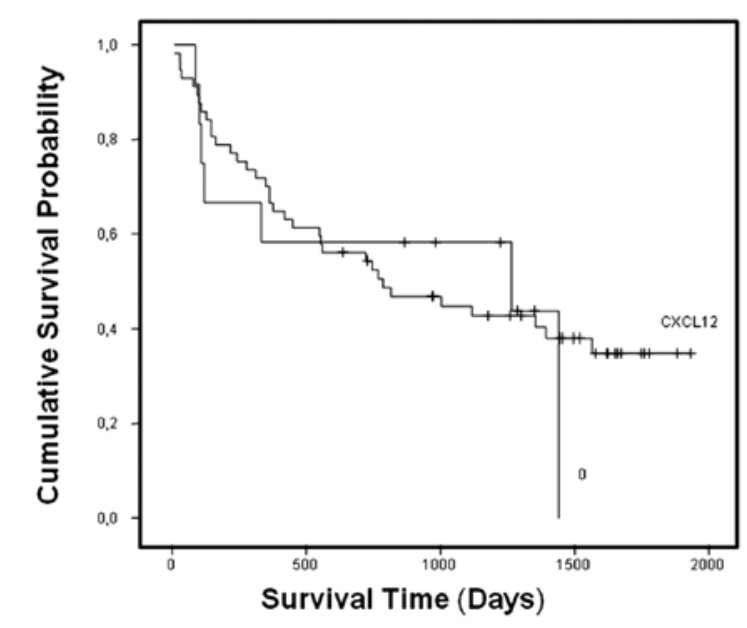

Figure 4. Survival of patients with CXCL12 expression (CXCL12=1-3) vs. patients with no CXCL12 expression (CXCL12=0).
Multivariate analysis: independent predictors of metastasis. Multivariate analysis demonstrated that pT-category $(\mathrm{P}=0.0089)$ and CXCL12 polymorphisms (GA, AA) $(\mathrm{P}=0.0194)$ were independent prognostic indicators of metastasis (M1) (Table IV).

\section{Discussion}

Metastasis is a frequent cause of death in patients with gastric cancer and can often occur after surgery, with absent or minimal lymph node involvement and without intra-operative macroscopic signs of peritoneal carcinomatosis. Even early stages are at risk: once tumor cells have spread through the mucosa infiltration level $3(\mathrm{~m} 3)$ and to the submucosa, the probability of metastasis increases rapidly and the likelihood of prolonged disease-free survival diminishes (14). Thus, it is of major importance to identify those patients with a high risk for metastatic disease. Apart from hematogenous invasion in organ metastasis, peritoneal carcinomatosis of gastric carcinoma may develop from direct cancer cell dissemination into the abdominal cavity. The expression of chemokine receptors by tumor cells can be an important factor with regard to tumor cell dissemination and organ-specific metastases (15-17).

CXCL12 (SDF-1) is the natural ligand of CXCR4, being a member of the CXC family that exerts chemotactic activity for hematopoietic progenitor cells (18). Thus far, chemokine signaling results in the transcription of target genes that are involved in cell invasion, motility, interactions with the extracellular matrix (ECM) and survival (19).

Analyzing human clinical samples of malignant ascitic fluids from patients with gastric cancer and peritoneal carcinomatosis, Yasumoto et al detected high concentrations of CXCL12 (20). In addition, CXCR4 positivity of the respective primary gastric carcinomas significantly correlated with development of peritoneal carcinomatosis ( $\mathrm{P}>0.001)$, concluding that the CXCR4/CXCL12 axis plays an important role in the development of peritoneal carcinomatosis from gastric cancer (20). In contrast, Tsuboi et al found that in pT3-stage gastric cancer patients, the CXCR4/CXCL12 axis was more strongly associated with lymphatic or hematogenous metastasis as compared to the establishment of peritoneal deposits (21). On

Table IV. Multivariate analysis: Independent predictors of metastasis.

\begin{tabular}{lcccc}
\hline & Regression coefficient B & Standard error & 95\% confidence interval & Significance (P-value) \\
\hline pT-category & $\mathbf{2 . 2 0 8 5}$ & $\mathbf{0 . 8 4 3 7}$ & $\mathbf{1 . 7 4 2 - 4 7 . 5 6 9}$ & $\mathbf{0 . 0 0 8 9}^{\mathrm{a}}$ \\
pN-category & 0.2902 & 0.4222 & $0.584-3.058$ & 0.4919 \\
Grading & 1.1945 & 0.8894 & $0.578-18.874$ & 0.1793 \\
CXCL12 polymorphism & & & & $\mathbf{0 . 9 7 6 - 1 5 4 . 6 0 7}$ \\
$\quad$ GA, AA & $\mathbf{1 . 4 4 6 9}$ & $\mathbf{0 . 6 1 9 1}$ & $0.163-23.679$ & $\mathbf{0 . 0 1 9 4}$ \\
$\quad$ GG & -0.3856 & 0.6035 & & 0.5228 \\
CXCL12 & & & & 0.3258 \\
1 & 0.7507 & 0.7640 & $0.589-168.781$ & 0.2345 \\
2 & 0.8082 & 0.6799 & $0.236-73.025$ & 0.9273 \\
\hline
\end{tabular}

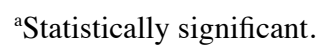


the other hand, there was a trend towards correlation of expression of these molecules with recurrences to the distant lymph nodes and the liver, although the number of events was too low to reach statistical significance. In the study by Ishigami et al, cancerous CXCL12 positivity was determined to be an independent prognostic factor in gastric cancer, with CXCL12-positive samples showing more aggressive behaviour (13). Immunohistochemical staining showed clear CXCL12 expression in both the tumor cell membrane and the cytoplasm. The authors concluded that an autocrine CXCL12 secretion from tumor cells might activate CXCR4 on the tumor cells, resulting in distant metastases.

The interaction of gastric cancer-expressed CXCR4 and SDF-1 $\alpha$ may be a key event in directing malignant cells to homing organs, which is underlined by findings in esophageal cancer, where the presence of micrometastatic tumor cells in lymph nodes and bone marrow was associated with poorer survival $(22,23)$. As demonstrated in pancreatic cancer, CXCL12 is secreted by cancerous lesions and flows via lymphatic or venous routes to its metastatic sites (24).

In our analysis, expression of CXCL12 and its polymorphisms did not exert an influence on overall survival. However, the CXCL12 polymorphism GA/AA significantly correlated with distant metastasis. In contrast, Ishigami et al observed a significant impact of CXCL12 expression intensity on survival $(\mathrm{P}<0.01)$ (13). Furthermore, CXCL12 expression was an independent prognostic factor, together with age, depth of tumor infiltration and lymph node involvement in multivariate analysis in their data.

The impact of SNP rs 1801157 of CXCL12 on tumorigenesis is a promising new target for oncological research. Our results showed that the homozygote (AA) and the heterozygote mutation (GA) of the CXCL12 gene were associated with distant metastasis $(\mathrm{P}=0.026 ; \mathrm{P}=0.0194$ in multivariate analysis, respectively). As a matter of fact, patients carrying the polymorphism may tend to have a worse prognosis. However, due to the intended limited number of M1 cases in our study population, we could not measure the clear impact on survival.

The existence of the SNP rs1801157 of CXCL12 in different tissues has been examined in previous studies. The occurrence of the polymorphism in colorectal cancer (CRC) was analyzed by Dimberg et al and Hidalgo-Pascual et al in two recent studies, while Hidalgo-Pascual et al stated no impact of the polymorphism on the localization of the CRC, Dimberg et al found out that CXCL12 polymorphism was associated with a colonic rather than with a rectal localization of the tumor $(25,26)$. Chang et al continued these analyses. According to his results, patients with $\mathrm{CRC}$, who carry the $\mathrm{G}>\mathrm{A}$ mutation in the CXCL12 gene, develop significantly more lymph node metastases and have a significantly poorer prognosis than CRC patients without the CXCL12 mutation (27).

Two studies concerning Iranian and Greek women compared the incidence of the G>A mutation of CXCL12 in breast cancer patients with a control group. The mutation was found significantly more often in the patient group as compared to controls $(28,29)$. These data suggest that CXCL12 polymorphism might contribute to tumor development in breast cancer patients. However, the association of CXCL12 polymorphism with gastric tumor development has not yet been analyzed and might be an interesting target for future research. These findings imply a major influence concerning the occurrence of the SNP rs1801157 in tumor patients. The exact impact of the polymorphism on the various tumor entities has not been sufficiently evaluated.

With the results of our current study and the previous literature in mind, it is most attractive to clinically introduce antagonists targeting CXCL12 or the CXCR4/CXCL12 axis signaling pathways as potential novel therapeutic regimens in human gastric carcinoma. Yasumoto et al showed in their xenograft nude mouse model not only that CXCL12 induces chemotactic responses, cell proliferation and a rapid phosphorylation of Akt and ERK in NUGC4 (human gastric carcinoma cell lines derived from malignant ascites) cells expressing CXCR4 at high levels, but also that treatment with the CXCR4 antagonist AMD3100 $(30,31)$ significantly suppressed the development of peritoneal carcinomatosis in their model (20). Further studies should evaluate targeting the CXCL12 signal as a new therapeutic option in selected patients with esophagogastric adenocarcinoma.

\section{Acknowledgements}

This paper contains parts of the doctoral thesis of Mareike Jordan.

\section{References}

1. Yoshie O, Imai $\mathrm{T}$ and Nomiyama H: Novel lymphocyte-specific CC chemokines and their receptors. J Leukoc Biol 62: 634-644, 1997.

2. Gerard C and Rollins BJ: Chemokines and disease. Nat Immunol 2: 108-115, 2001.

3. Muller A, Homey B, Soto H, et al: Involvement of chemokine receptors in breast cancer metastasis. Nature 410: 50-56, 2001.

4. Mashino K, Sadanaga N, Yamaguchi H, et al: Expression of chemokine receptor CCR7 is associated with lymph node metastasis of gastric carcinoma. Cancer Res 62: 2937-2941, 2002.

5. Scotton CJ, Wilson JL, Scott K, et al: Multiple actions of the chemokine CXCL12 on epithelial tumor cells in human ovarian cancer. Cancer Res 62: 5930-5938, 2002.

6. Oonakahara K, Matsuyama W, Higashimoto I, Kawabata M, Arimura K and Osame M: Stromal-derived factor-1alpha/ CXCL12-CXCR 4 axis is involved in the dissemination of NSCLC cells into pleural space. Am J Respir Cell Mol Biol 30: 671-677, 2004.

7. Kucia M, Jankowski K, Reca R, Wysoczynski M, Bandura L, Allendorf DJ, Zhang J, Ratajczak J and Ratajczak MZ: CXCR4SDF-1 signalling, locomotion, chemotaxis and adhesion. J Mol Histol 35: 233-245, 2004.

8. Kucia M, Reca R, Miekus K, Wanzeck J, Wojakowski W, Janowska-Wieczorek A, Ratajczak J and Ratajczak MZ: Trafficking of normal stem cells and metastasis of cancer stem cells involve similar mechanisms: pivotal role of the SDF-1-CXCR4 axis. Stem Cells 23: 879-894, 2005.

9. Schimanski CC, Schwald S, Simiantonaki N, Jayasinghe C, Gönner U, Wilsberg V, Junginger T, Berger MR, Galle PR and Moehler M: Effect of chemokine receptors CXCR4 and CCR7 on metastatic behaviour of human colorectal cancer. Clin Cancer Res 11: 1743-1758, 2005.

10. Gockel I, Schimanski CC, Heinrich C, Wehler T, Frerichs K, Drescher D, von Langsdorff C, Domeyer M, Biesterfeld S, Galle PR, Junginger T and Moehler M: Expression of chemokine receptor CXCR4 in esophageal squamous cell cancer and adenocarcinoma. BMC Cancer 6: 290, 2006.

11. Wehler T, Wolfert F, Schimanski CC, Gockel I, Herr W, Biesterfeld S, Seifert JK, Adwan H, Berger MR, Junginger T, Galle PR and Moehler M: Strong expression of chemokine receptor CXCR4 by pancreatic cancer correlates with advanced disease. Oncol Rep 16: 1159-1164, 2006. 
12. Schimanski CC, Bahre R, Gockel I, Müller A, Frerichs K, Hörner V, Teufel A, Simiantonaki N, Biesterfeld S, Wehler T, Schuler M, Achenbach T, Junginger T, Galle PR and Moehler M: Dissemination of hepatocellular carcinoma is mediated via chemokine receptor CXCR4. Br J Cancer 95: 210-217, 2006.

13. Ishigami S, Natsugoe S, Okumura H, Matsumoto M, Nakajo A, Uenosono Y, Arigami T, Uchikado Y, Setoyama T, Arima H, Hokita S and Aikou T: Clinical implication of CXCL12 expression in gastric cancer. Ann Surg Oncol 14: 3154-3158, 2007.

14. Hölscher AH, Drebber U, Mönig SP, Schulte C, Vallböhmer D and Bollschweiler E: Early gastric cancer: lymph node metastasis starts with deep mucosal infiltration. Ann Surg 250: 791-797, 2009.

15. Strieter RM: Chemokines: not just leukocyte chemoattractants in the promotion of cancer. Nat Immunol 2: 285-286, 2001.

16. Rempel SA, Dudas S, Ge S and Gutierrez JA: Identification and localization of the cytokine SDF1 and its receptor, CXC chemokine receptor 4 , to regions of necrosis and angiogenesis in human glioblastoma. Clin Cancer Res 6: 102-111, 2000.

17. Murphy PM: Chemokines and the molecular basis of cancer metastasis. N Engl J Med 345: 833-835, 2001.

18. Jo DY, Rafii S, Hamada T and Moore MA: Chemotaxis of primitive hematopoietic cells in response to stromal cell-derived factor-I. J Clin Investig 105: 101-111, 2000.

19. Locati M, Deuschle U, Massardi ML, Martinez FO, Sironi M, Sozzani S, Bartfai T and Mantovani A: Analysis of the gene expression profile activated by the CC chemokine ligand 5/ RANTES and by lipopolysaccharide in human monocytes. J Immunol 168: 3557-3562, 2002.

20. Yasumoto K, Koizumi K, Kawashima A, Saitoh Y, Arita Y, Shinohara K, Minami T, Nakayama T, Sakurai H, Takahashi Y, Yoshie O and Saiki I: Role of the CXCL12/CXCR4 axis in peritoneal carcinomatosis of gastric cancer. Cancer Res 66 : 2181-2187, 2006

21. Tsuboi K, Kodera Y, Nakanishi H, Ito S, Mochizuki Y, Nakayama G, Koike M, Fujiwara M, Yamamura Y and Nakao A: Expression of CXCL12 and CXCR4 in pT3-stage gastric cancer does not correlate with peritoneal metastasis. Oncol Rep 20: 1117-1123, 2008.
22. Thorban S, Roder JD, Nekarda H, Funk A, Pantel K and Siewert JR: Disseminated epithelial tumor cells in bone marrow of patients with esophageal cancer: detection and prognostic significance. World J Surg 20: 567-572, 1996.

23. Thorban S, Rosenberg R, Busch R and Roder RJ: Epithelial cells in bone marrow of oesophageal cancer patients: a significant prognostic factor in multivariate analysis. $\mathrm{Br} \mathrm{J}$ Cancer 83: 35-39, 2000.

24. Koshiba T, Hosotani R, Miyamoto Y, Ida J, Tsuji S, Nakajima S, Kawaguchi M, Kobayashi H, Doi R, Hori T, Fujii N and Imamura M: Expression of stromal cell-derived factor 1 and CXCR4 ligand receptor system in pancreatic cancer: a possible role for tumor progression. Clin Cancer Res 6: 3530-3535, 2000.

25. Dimberg J, Hugander A, Löfgren S and Wågstäter D: Polymorphism and circulating levels of the chemokine CXC12 in colorectal cancer patients. Int J Mol Med 1: 11-15, 2007.

26. Hidalgo-Pascual M, Galan J, Chaves-Conde M, RamírezArmengol JA, Moreno C, Calvo E, Pelaez P, Crespo C, Ruiz A and Royo JL: Analysis of CXCL12 3'UTR G>A polymorphism in colorectal cancer. Oncol Rep 18: 1583-1587, 2007.

27. Chang SC, Lin PC, Yang SH, Wang HS, Li AFY and Lin JK: SDF-1alpha G801A polymorphism predicts lymph node metastasis in stage T3 colorectal cancer. Ann Surg Oncol 16: 2323-2330, 2009

28. Razmkhah M, Talei AR, Doroudchi M, Khalili-Azad T and Ghaderi A: Stromal cell-derived factor-1 (SDF-1) alleles and susceptibility to breast carcinoma. Cancer Lett 225: 261-266, 2005.

29. Zafiropoulos A, Crikas N, Passam AM and Spandidos DA: Significant involvement of CCR2-641 and CXCL12-3a in the development of sporadic breast cancer. J Med Genet 41: e59, 2004.

30. Rubin JB, Kung AL, Klein RS, et al: A small-molecule antagonist of CXCR4 inhibits intracranial growth of primary brain tumors. Proc Natl Acad Sci USA 100: 13513-13518, 2003.

31. De Clercq E: Recent advances on the use of the CXCR4 antagonist plerixafor (AMD3100, Mozobil ${ }^{\mathrm{TH}}$ ) and potential of other CXCR4 antagonists as stem cell mobilizers. Pharmacol Ther 128: 509-518, 2010. 